\title{
School bonding, attachment, and engagement through remote learning: Fostering school connectedness
}

New Zealand Journal of Teachers' Work, Volume 18, Issue 2, 91-108, 2021

\author{
JENNIFER CHARTERIS ${ }^{1}$ \\ ANGELA PAGE ${ }^{2}$ \\ ${ }^{1}$ University of New England, Australia; ${ }^{2}$ University of Newcastle, Australia
}

\begin{abstract}
Over 2020 and 2021 we have seen significant disruption to schooling across the world as COVID-19 forces school closures. Education sectors migrated to distance learning arrangements and teachers and students primarily communicated through digital means. Under challenging conditions, school leaders and teachers made rapid changes to pedagogy and curriculum to accommodate their students' diverse range of learning needs. We present an interview drawn from a qualitative study undertaken in Australia to illustrate (from a teacher's perspective) how a school response to COVID-19 integrates elements of school connectedness during the shift to distance learning. School connectedness is an umbrella term that has been theorised in many different ways. In this article, we illustrate school bonding, attachment, and engagement as three interrelated aspects of school connectedness that came to the fore during lockdown measures associated with COVID-19. Leaders, teachers, students, and school communities benefit from school connectedness. When adversity is experienced, school connectedness can be seen in the relationships between teachers, the commitment to students, and the all-important pastoral support from school leaders. Strong and supportive relationships develop through practices that support school bonding, school attachment, and school engagement.
\end{abstract}

\section{INTRODUCTION}

Around the world, countries have responded to the COVID-19 epidemic by closing schools and moving students to distance education. In 2020 school closures impacted the schooling of 1.5 billion learners (84\% worldwide total) in 169 countries of the world (Buonsenso et al., 2021). It has been estimated that students around the world have lost between 0.3 to 0.9 years of schooling (Azevedo et al., 2020). In addition to the lost months of formal learning, there are also concerns that students experience a negative impact on their mental health (Merry, et al., 2020). The effects of COVID-19 have a disproportionate influence on students, with students from low socioeconomic status, students with 
additional needs, and Indigenous students experiencing the biggest challenges to their education (Flack et al., 2020).

In our research, we examine aspects of school connectedness (school bonding, engagement and attachment) and use an interview to illustrate how a school response to COVID-19 integrates elements of this construct during the shift to distance learning. Connectedness, a feeling of belonging to or having affinity with a particular person or group, is a primary focus of all educational settings, and it is an important for successful learning. A sense of peace, wellbeing, and belonging are key facets of 'school connectedness.'

We commence this article by contextualising the research in Australia during the COVID-19 lockdowns. We then describe school connectedness and signal its importance when schools undergoing closures in response to COVID19. A rationale is provided for fostering attachment and engagement between teachers, students, and communities. An interview is used to illustrate a distance learning context where students who have both additional learning needs and experience social disadvantage are expected to shift in their mode of study. Considerations for practice that support school connectedness are provided in a move to inform ongoing conversations on how to foster school bonding, attachment, and engagement.

\section{TEACHING DURING THE COVID-19 LOCKDOWNS}

Over the last two years, educators in Australia have moved in and out of lockdowns, working from both home and school in a hybridised work model. In Australia the first confirmed COVID-19 case emerged in Australia on 25 January 2020. Cases of coronavirus swelled in February and March, and by 20 March Australia had sealed its borders to non-residents. By the 23 March, the Prime Minister announced that he would prefer schools to remain open, with parents given the option to permit their children to attend or not. However, at the end of March NSW schools transitioned to distance learning which lasted several weeks. Victoria suffered sequential lockdowns in 2020 and 2021 with residents enduring over 200 days of restriction. Although NSW has fared better, by August 2021 schools were closed again and students moved to distance learning. With the move to close schools with the COVID-19 pandemic, educators and the NSW Department of Education worked hard at short notice to find ways to support the learning of students who were to be educated at home.

\section{School Connectedness}

School connectedness can be seen as a multidimensional construct (GarcíaMoya et al., 2019) which encompasses positive relationships with encouraging adults and peers; a sense of belonging; a commitment to learning, and the experience of a safe and supportive environment (Author et al., 2021). There are a range of key features that can be linked with school connectedness as a construct. These include:

- students' perceptions of healthy and positive relationships experienced within the school environment; 
- an individual experience of care, respect and support, positive feelings of liking or enjoying school;

- students' positive feelings towards the school as a community (GarcíaMoya et al., 2019).

The notion of school connectedness helps to explain how students can sometimes experience detachment, where they have a sense of disconnection and isolation (Cumming et al., 2017). So important is connectedness, that there is evidence to suggest that it can help to moderate the damaging effects of bullying, with those who experience more connection with school less likely to report suicidal behaviour (Kim et al., 2020). School bonding, attachment, and engagement are three aspects of school connectedness (See Figure 1.) that we argue are important features of a school's response to lockdown measures associated with COVID-19.

Figure 1: Integral components of school connectedness

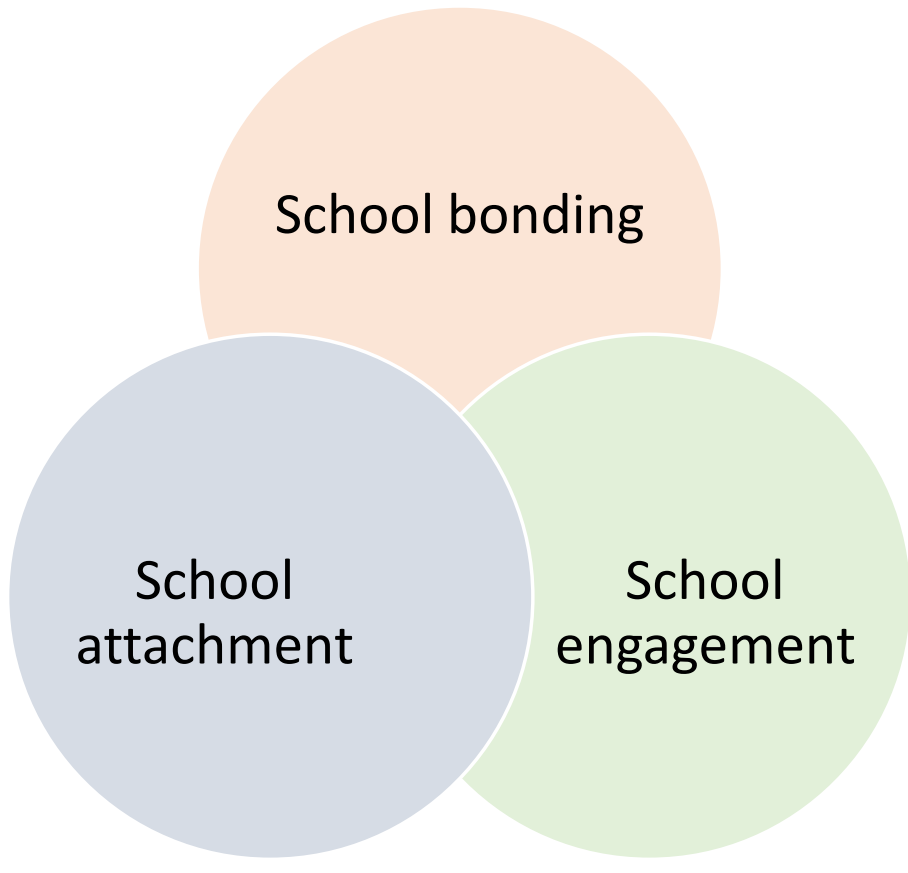

\section{School bonding}

School bonding can be described as the extent to which students feel close to people at their school, feel a part of their school, and are happy to be at their school (Johnson et al., 2001). School bonding has a range of beneficial elements. There is a research base to suggest that school bonding can be linked with academic achievement and motivation, and high levels of happiness (Maiya et al., 2021). During the COVID-19 pandemic when students were asked to study from home, school bonding became an important feature of that extended sense of community and connection with the school as an organisation. 


\section{School attachment}

School attachment pertains to how students experience school (Libbey, 2004). In short, it is the emotional feeling of fondness for, and an enjoyment of school (Goodenow, 1993). Schools are places where there is social interaction, the development of social skills, peer groups are established, and one learns to express oneself and form one's identity (Henry \& Slater, 2007). School attachment encompasses how student feel they are accepted and liked by peers and teachers, their enjoyment of being at school and their sense of connectedness where they feel like participating members of the school community (Catalano et al., 2004). Adult support and peer relationships have a positive influence on and help to maintain school attachment (Blum, 2005). Over 2020 and 2021 the school lockdown periods had an impact on school attachment for students with additional needs (Author et al., 2021).

\section{School engagement}

As we have written elsewhere, school engagement can be linked with students' commitment to schooling practices (Page et al., 2021). Behavioural, cognitive and emotional engagement are all aspects of school engagement (Fredricks et al., 2005). When there is behavioural engagement student attend school regularly, are punctual to class, complete work in the classroom, submit homework regularly, engage in school discussion and various activities and contribute to extracurricular activities (Farrington et al., 2012). Emotional engagement involves students' reactions to teachers, classmates, and the school and it forges ties with the institution itself (Fredricks et al., 2005). Cognitive engagement involves students' willingness to put in the energy and effort required to tussle with complex ideas, accomplish challenging skills. It can be described as "students' [willingness to] allocate varying amounts of cognitive resources for different strategies in learning" (Li \& Lajoie, 2021, p. 2).

Having elaborated on the different aspects of school connectedness we address in this article, we now give consideration to students with additional needs who are expected to transition to home learning during the pandemic.

\section{Students with additional educational needs and lockdowns}

It can be difficult for parents when students with additional needs are required to stay home without the support of structures at school. While there are report of psychological distress amongst Australian adults during extended periods of lockdown, children's mental health and well-being have also been signalled as a significant area of concern (Bessell, 2021). As Asbury et al. (2021, p. 1772) observe, "carefully developed routines have been disrupted; support networks have disintegrated; and parents have been asked to do a job that trained teachers find challenging, without any training." Moreover as Patel (2020), suggests, the closure of schools and a shift to online learning means that students can be without necessary assistive technologies and there can be increased levels of stress and anxiety among children with additional needs and their parents. As an example, schools in Victoria, Australia endured six lockdowns over the 20202021 period with over 200 days in lockdown. The Victorian Department of Education and Training (VicDET) (2021, online) signalled how the lockdown affected groups of students in the state. 


\begin{abstract}
Attendance was also lower for some at-risk or vulnerable groups, including students in out-of-home care, some students from English as Additional Language backgrounds such as students from refugee backgrounds, and students at-risk of disengaging from school.
\end{abstract}

Furthermore in Australia, Victorian teachers also reported that the students who found the transition to distance education most difficult have: lower levels of English; home-learning environments that are not conducive to study; and/or require educational and health and wellbeing supports that are provided at school but are unavailable at home (VicDET, 2021). In Aotearoa New Zealand context Hood (2020, p. 4) tells us:

The lockdown period shone a light on the range of existing inequities, disparities and divides within New Zealand's education system, as well as potentially exacerbating them. The most immediately apparent embodiment of this inequality was those students who did not have access to a device or internet connection at home to enable them to engage with online learning opportunities.

\title{
NARRATIVE STUDY
}

This article explores an interview that was part of a small narrative study undertaken in Australia. The research considered in what ways, if any, was school connectedness enabled for students with special educational needs during the COVID-19 pandemic? The semi-structured interview (Corbin \& Strauss, 2014) was with an experienced teacher, Janet, who works with students who have additional needs. She holds a position as the 'Head Teacher -Learning and Support' in the school. Janet's interview lasted approximately 30 minutes in length and took place through Zoom. Janet's interview was analysed thematically against the conceptual framework presented in Figure 1.

In order to maintain Janet's confidentiality and anonymity, pseudonyms have been used for her and the school's name. Janet is a teacher at Cowendale School, which has a total of 210 students and is in a regional area. She describes how the school services a community where there is multi-generational disadvantage. The principal was very proactive in sourcing computers from the Department of Education as only $10 \%$ of the students had access to computers and the Internet at home. Because the school was one of the 12th lowest socioeconomic areas in the state, 74 laptops and internet access points were sent out to them.

Janet works in the special unit. She describes her students as a high risk low socioeconomic group who come "from high trauma backgrounds, and/or have undiagnosed mental health issues." The experience of teaching during the lockdown period required Janet to teach both online and face to face. In the regional area of Australia where this study took place, essential workers could drop their children to school so they could work. Janet describes the complexity of working face to face and simultaneously managing a class online: 
It was a strange situation...We've had kids show up at school the whole time, like schools were never closed....That was tricky. Because if you've got three students here in class and you're teaching them, you can't be online teaching at the same time. So, yeah, it's been quite demanding on teachers.

Quotations have been selected from Janet's interview to illuminate the aspects of school connectedness (bonding, engagement, and attachment) for both teachers and students.

\title{
School bonding at Cowendale
}

When the 2020 lockdown occurred the discourse changed for the teachers to one where there and there was little phatic communion. Janet reported that they respected the health orders, as some members of the community were vulnerable. Yet the sense of isolation was difficult because there were few opportunities to talk informally. She found that conversations for focused on how people were managing their students in the hybrid model of teaching.

\begin{abstract}
We didn't see each other... We worked in isolation in our classrooms because we couldn't be near each other. So, we didn't have any staff meetings or anything like that. It's just been by email.... We've got a few people here in our high risk group. So, everyone was really respectful. Yeah, I missed it. I miss the close contact. I miss having a chat. It was very focused on business. Like, I mean, we're always focused on teaching, but it was like wasn't like how was your weekend? ... It was more like, "Oh my God, how is your year eight going? How's year nine going?"
\end{abstract}

The experience created a sense of solidarity between the teachers as they shared resources and provided each other with messages of moral support. This created a sense of solidarity.
Everyone was helping each other. A couple of teachers loaded help sheets on how to do complex things in Google Classroom. Some of the teachers put how to log into these other sites. It was great. The teachers put really nice wellbeing sort of comments into our staff communication. Like "Make sure we look after ourselves", "Take a break." You know, "You're all doing great." Those types of things.

School connectedness and, more specifically, school bonding was promoted by the principal in a deliberate act of support and Janet expressed appreciation for his ethic of care in the way that he ensured the teachers had the equipment they needed for their work at home. He voiced concern for their physical and mental wellbeing.

The principal was incredible. He was just so supportive. He said work from home on the days you can. Please come in and get your office chair. Make sure you're sitting comfortably ... We all had laptops given 
to us. He was just so accommodating. People were taking their desk and their chair home. He was told us, you know, you have to make sure you don't get fatigued....

Recognising the challenges associated with looking after students at school and teaching them remotely, the principal ensured flexibility in teaching arrangements.

Our principal was particularly supportive. He made sure that only a skeleton staff was here every day, and he rostered us so that we worked from home almost every day. We only worked one day to fortnight face-to-face here at school ... So, he rotated everyone fairly. I just found him incredible. I just thought, wow, we all felt really safe and supported at school and at home.

The ethic of care was extended to the school community. The principal modelled this ethic by dropping of resources for the families in need. Janet said that he created a sense of solidarity among the teaching staff, as they worked together to support the school community.

He went around to the students' houses. He dropped off laptops. He dropped off groceries one day. Yeah, we felt like we really all work together to help the kids.

Teachers worked hard to contact the school community in order for students to be provided with the pastoral care they needed. Janet said she tried multiple ways to contact families.

So, we phoned every parent and made sure they all had the Google Classroom codes. I think phoning was the best. We tried email but we didn't get any responses. We tried texting, but phoning people was great. We said, you know, "I need them to log on to their classroom. Here's the code. Can you make sure they have the code?" We divided up the students and we all made sure we contacted our students once a week.

There was differentiation in this pastoral care approach, as Janet contacted her students with additional needs twice a week. In order to transcend disadvantage and ensure there was connectivity in the household for her student, Janet drove to their home to install the Internet.

My students were twice a week because I had the high risk group [who experience] social disadvantage, I had to make sure they were safe. So, l'd phone the parent up and just say, "Look, they haven't logged on in the last two days or done any work. You know, could you try and encourage them." And one family said, "Well, I just don't know how to use the internet thing." So, I had to drive out to their house, which was a little bit stressful. They brought the computer out to the veranda and 
I set it up for them. And then I left. And that was great, because at least I knew they had an Internet connection.

\section{School attachment at Cowendale}

Janet's interview suggests that there was a strong commitment to school attachment at Cowendale school. With the school closed to most students, Janet and the principal brought the school to the families when they needed internet connection and pastoral support (e.g., dropping off food).

I feel like we just, you know, we were supposed to go to their house. And here I am sitting on the veranda trying to fix their laptop and the principal is dropping groceries off. I just think you just can't survive unless you're like that.

Attachment was a challenge when connection for students was intermittent. Families who had not previously had access to the Internet in their homes commandeered the equipment that students needed for school.

We have a couple of kids [who] reported that their carers or parents used the school laptop, like because they never had one. The kid said, "We couldn't go and do our work because, you know, mum was on the computer." It was a big adjustment for the families too, and it probably was the first time they had a laptop in the house with an Internet connection.

Janet noted that parents would come to school and tell her that their child was refusing to undertake their lessons. These parents had already previously been into the school for meetings about similar issues with their child. The move to a home learning situation did not improve the engagement with school content. Janet was able to have a conversation with a parent about finding different approaches to motivate their child to learn. In turn, the parent developed her skills with the educational software used by the school.

So, we were trying to explain to her that there are different ways we can support them and she was saying that she had to learn how to use Google Classroom and Education Perfect. And she'd learned all this stuff that she had no skills in before...So, it's good. It was good feedback.

Janet said that the experience of having their children schooled at home "was a big wake up" for parents. It gave them an insight into their children that perhaps they did not have before. Some parents struggled to support their child with home schooling and they could not get their child to log in to the software. Although they were not 'essential workers' they dropped their child off saying "I can't deal with them anymore."

School attachment was evident in the way that Janet described how students used social media as a chance to connect with peers. Janet described how the year-nine advisor had developed a pastoral support group. She set up 
Google Classroom where students checked in with her each day and they could connect with their peers. The year advisor asked them to answer "a few funny questions" and share something about their day which she believed the student enjoyed. However many of the students had made their own community and did not need the online school space to connect.

But I think a lot of the kids were connected on social media anyway. We had a lot who were connected through gaming. They said they were playing PlayStation 4 games, and they had a headset with a microphone, and they were like talking to their school friends.

Janet found this problematic as she said: "I would rather them be doing school work." When the IT teacher noted that the students preferred to connect with peers rather than doing their school work, he ran a trial to create connections with and between students.

Our IT teacher, who's our science teacher, ran a trial and he got Google Classroom working on an Xbox 360 . So, that was a really good trial, which meant that kids could actually get to their Google Classroom on their Xbox and it worked...But they needed a keyboard, whereas most of them just have the game controller. To actually use it properly, you would have needed an Xbox keyboard. But, you know, it was still everyone was just trying their best to connect with the kids.

The emphasis on school attachment emerged through necessity. Janet commented that the emphasis on innovation to connect with students was a response to the challenge of working with students who were "difficult."

I think, because we're such a difficult school, we've always been a staff where everyone's always trying new things. We've such difficult kids in our school that I don't think you'd survive here if you weren't always trying something new, or trying to do this or trying to do that. It's just the nature of our school.

\section{School engagement at Cowendale}

The lessons occurring through the use of technology in the home provided an affordance for parents to witness their child's engagement with their schooling. Janet reported that, in some instances, there was parental support for student engagement. She described how a parent ensured that her 13 year son was completing tasks and submitting work.

Some teachers added parents to the classroom as observers because then they could see whether their child was up to date and that's really good. I had a parent meeting and that mum said that she just kept checking her son's classroom. They can't have any input into it, but she could just check and see that he had handed things in. They can't see what other students are doing, but they could see that their own child was up to date... It's really good because she was able to support 
him and say "you've got something in your history classroom and you haven't handed it in."

School engagement can be challenging when the day-to-day and moment-by moment clarification conversations that take place between teachers and students are mediated through technologies. Janet described how some students missed out on receiving the clarification they needed when they would have benefited from her providing contextualisation for content and reframing of material.

Today a mum said that her son missed [the teacher] putting things in context. Like those little hints - those little reframing of things. But we've had to work within the time constraints and within the technology constraints. So it might not have suited all students. But it suited some. Because, you know, they weren't lost in the extra explanations. It kept everyone focused. But some kids need that little reframing and those little hints and those extra little things that teachers say.

Janet said that the students in the 'special class' she works in come from high trauma backgrounds and they find it hard to engage at school. She believes that there are many undiagnosed mental health and undiagnosed medical conditions who find learning at school difficult. Unsurprisingly, she observes that these are the same students who are difficult to engage at school. She commented that she took small steps to engage the students to participate in their lessons.

We praised any effort even logging on. In my Google Classroom I had question of the day like, "what's the most awesome thing about not going to school today?" Just anything to get them to answer because then I made that connection. Then I try and lead them into a bit of work.... It was the same kids. It wasn't a magic wand. It didn't fix anybody. But you know, we gave it a go.

Janet said that it was "concerning" that students who didn't have access to school were slipping behind. She commented:

They were already behind the eight ball. I think we're going to see a bigger divide. And we tried, I mean, we tried our best. We couldn't have done any more, but we still have kids who didn't engage in it at all, you know, despite our best efforts.

Janet believed that about $20 \%$ of students did not engage in learning online. She said that they "just did nothing, but just played", as she could not contact the students or the students were school refusers.

Some on my list, I just couldn't contact. Some parents would just say, “Look, they just won't do it. They're not going to do it." They wouldn't have a bar of it and they just don't have the parenting skills.... There's nothing more we could have done. The principal tried his hardest. We 
tried our hardest... we'll just see what it's all like when they come back and what a divide there is.

\section{DISCUSSION}

One of the strengths of narrative study research is its relatability. While the experience described in Cowendale School cannot be generalised, there may be resonances for practitioners in other schools. The focus of this article is to provide an illustration of the elements of school connectedness - school bonding, attachment, and engagement in relation to a school where there is social disadvantage. Janet has a particular lens as her pupils have additional learning needs.

\section{School bonding}

Janet's interview comments suggest that the teachers' relationships became mostly mediated through technologies and the day to day processes that enable school bonding changed. The way teachers and students spoke and related to each other shifted and they engaged in less small talk. Yet there was a sense of solidarity. The teachers found technology enabled them to provide pastoral care and support for each other also.

Linked with school bonding is an ethic of care. This was demonstrated by the school principal who expressed kindness and thoughtfulness for the teachers' physical and mental well-being. Janet's interview suggests that it was appreciated by the teachers. There was flexibility in the way that the school was managed and structures were put in place that supported school bonding. The teachers were able to work from home, in a way that suited them and help them feel safe and supported.

This ethic of care extended to the families in the community. Janet's comments highlight that the principal and the teacher went the extra mile, for example, to provide Internet connectivity and sustenance for families.

\section{School attachment}

School attachment is fostered through relationships. Janet's interview indicates that, under the COVID-19 schooling arrangements, adjustments were made in the relationships between teachers, students, and parents and carers. Parents who took an interest were able to develop new skills and learn to use the software their children needed to access in their education.

Although Janet mentioned that teachers like the year-nine advisor, made an effort to create connection and attachment, through the online platform, some students found their own peer communities, and elected not to participate in the school sanctioned environment. They chose, for example, to play online PlayStation games with their peers. This highlights that when school closures happen, some students may refuse to participate in lessons, especially those students who are not highly motivated in the first place. This can be problematic for teachers and students' progression, when students prefer to engage in gaming over the school activities planned for them.

Janet suggested that the teachers recognised that technologies lured students to other platforms and away from school online-learning environments. 
School attachment was instead fostered through the creative use of such technologies.

\section{School engagement}

Janet alluded to parent and caregiver school engagement through technology. She indicated that parents were able to take an active role in their child's education as they could see how their child participated in their studies and when assessments were due. The technology afforded school attachment, providing parents with an understanding of the child's progress, and how well they were learning and engaging with their school work.

Janet's interview also suggested that there was difficulty with the transition from face to face to online learning. Students who need more explanations to contextualise their learning could slip through the cracks and miss out. It remained a challenge to engage students who were already school refusers or found learning difficult. There was concern that students who were not engaging, were missing out on vital lessons. There was a divide between those students who were engaging and participating in the lessons with their teachers and those who had opted out.

While this is a small study and only one interview is presented here, we can suggest some considerations for practice on the basis of the research.

\section{Enhancing school connectedness for teachers}

Teachers can benefit from developing school connectedness. School connectedness is found in the relationships between teachers, the support from school leaders, and in the appreciation expressed by students and their whānau. An emphasis on strong and supportive relationships between all members of the school community can create important interconnections.

Teachers cannot create school connectedness on their own but can foster collegiality with colleagues and connection with and between students. It can be beneficial when school leader practices that support teachers are visible. Communication is important and decisions, especially when crisis leadership is required, need to be clearly articulated. Visibility and decisiveness are important elements of leadership during crises that foster connectivity (Mutch, 2015). We highlight that all teachers can be involved in all aspects of developing and maintaining school connectedness for students. This can provide teachers with a stake in the decision-making process and a sense that they are valued for their contributions.

School leaders may also consider providing additional professional development for teachers who need extra support to teach at distance through new technologies. For instance, this could involve teaching through a hybrid model where students are on site and online. Through fostering further opportunities to work in teams, teachers may be less likely to experience isolation.

\section{Enhancing school connectedness for parents and whānau}

If parents and whānau are at home with children, they may be able to assist in the home learning. However this is not always the case. Families can feel ill equipped to support their child academically and/or have many children of 
different ages to support with their schoolwork at home. This can prove challenging, especially if they are also trying to work from home. Parents and whānau are not replacement teachers. Existing relationships are important, as teachers liaise with parents around how to provide optimum opportunities for their children to learn.

Parents and whānau may need assistance to use technologies. While teachers may be able to provide internet based videos, websites, or even a podcast, support may be required for parents and whānau who experience technological problems and/or connectivity issues so children can access online education.

Many parents are daunted and even stressed about supporting their children to learn at home. It is an opportunity to celebrate the funds of knowledge (social and cultural practices) in the family and community (e.g., weaving, knitting, playing instruments, cooking). There is an opportunity to value the learning that happens in every day contexts.

It must not be overlooked that access to online education is a privilege and according to the Minister of Education, Chris Hipkins, in Aotearoa there are up to 100,000 children (about 80,000 households) without access to a digital learning device (Radio New Zealand, 2020). Janet signalled that up to $20 \%$ of Janet's students were not connected online. We therefore acknowledge social disadvantage can be exacerbated through the digital divide during lockdowns.

\section{Enhancing school connectedness for students}

To contribute to the development and maintenance of school connectedness for all children, and particularly students with additional learning needs, we advocate for the maintenance of effective communication, peer connectedness, and individual educational plans (Page et al., 2021). Effective communication is especially relevant for students with additional needs. A telephone call can be a simple solution to keep in touch.

Peer connectedness can be promoted for social or academic reasons. Where possible, it is appropriate to plan for and support peer connectedness. For high needs students, the individual educational plan may need to be adapted for periods of learning at home. There may need to be a shared agreement to refocus the activities and especially if a student requires a Specialist Service (e.g., speech therapist).

Janet indicated that it was difficult for students with disabilities to complete their set work and to accept that home-schooling was a legitimate form of education. Changes in routines affected students' willingness to engage in learning. Routines at home can be put in place by having schedules for school engagement (e.g., visual timetables).

\section{CONCLUSION}

Educators across the world are working in extraordinary times. Tesar (2021, p. 1) captures the tumultuous zeitgeist of the COVID-19 moment for educators:

The whole world, regardless of geographical location, has been facing unprecedented... turmoil, where forced entry into becoming a virtual classroom - an online space and virtual presence - started within a 
week, without much research, understanding, or particular thinking process. Such a rapid change for many of us created a rapid tension, insecurity, as well as predictions and ideas - looking back, analysing current conditions or contemplating the future.

The interview discussed in this article illustrates the importance of helping students to develop a sense of belonging and connectedness to their peers, teachers, and education in general. School bonding, attachment, and engagement can be regarded as key foci when schools aim to promote school connectedness during crisis events like COVID-19 lockdowns. With the rapidity of the fracturing we have seen in the day to day practices of schooling, connectedness is an important aspect of wellbeing that addresses the needs of individuals and school communities. 


\section{REFERENCES}

Asbury, K., Fox, L., Deniz, E., Code, A., \& Toseeb, U. (2021). How is COVID-19 affecting the mental health of children with special educational needs and disabilities and their families?.Journal of Autism and Developmental Disorders, 51(5), 1772-1780. https://doi.org/10.1007/s10803-020-04577-2

Azevedo, J. P., Hasan, A., Goldemberg, D., lqbal, S. A., \& Geven, K. (2020). Simulating the potential impacts of COVID-19 school closures on schooling and learning outcomes: $A$ set of global estimates (Policy Research Working Paper 9284). World Bank Group. https://elibrary.worldbank.org/doi/abs/10.1596/1813-9450-9284

Bessell, S. (2021). The impacts of COVID-19 on children in Australia: Deepening poverty and inequality. Children's Geographies, https://doi.org/10.1080/14733285.2021.1902943

Buonsenso, D., Roland, D., De Rose, C., Vásquez-Hoyos, P., Ramly, B., Chakakala-Chaziya, J. N., ... \& González-Dambrauskas, S. (2021). Schools closures during the COVID-19 pandemic: a catastrophic global situation. The Pediatric Infectious Disease Journal, 40(4), 146-150. https://doi.org/10.1097/INF.0000000000003052

Catalano, R. F., S. Oesterle, C. B. Fleming, and J. D. Hawkins. (2004). The importance of bonding to school for healthy development: Findings from the social development research group. Journal of School Health, 74(7), 252-261. https://doi.org/10.1111/j.1746-1561.2004.tb08281.x

Corbin, J., \&. Strauss, A. (2014). Basics of qualitative research: techniques and procedures for developing grounded theory. Sage publications.

Cumming, T. M., R. J. Marsh, and K. Higgins. (2017). School connectedness for students with disabilities: From theory to evidence-based practice. Routledge.

Farrington, C.A., Roderick, M., Allensworth, E., Nagaoka, J., Keyes, T . S., Johnson, D. W., \& Beechum, N. (2012). Teaching adolescents to become learners: The role of noncognitive factors in shaping school performance-A critical literature review, University of Chicago. Consortium on Chicago School Research.

García-Moya, I., Bunn, F., Jiménez-Iglesias, A., Paniagua, C., \& Brooks, F. (2019). The conceptualisation of school and teacher connectedness in adolescent research: A scoping review of literature. Educational Review, 71(4), 423-444. https://doi.org/10.1080/00131911.2018.1424117

Goodenow, C. (1993). The psychological sense of school membership among adolescents: Scale development and educational correlates. Psychology in the Schools, 30(1), 79-90.

Henry, K. L., \& Slater, M. D. (2007). The contextual effect of school attachment on young adolescents' alcohol use. Journal of School Health, 77(2), 6774. https://doi.org/10.1111/j.1746-1561.2007.00169.x

Hood, N. (2020). Learning from lockdown: What the experiences of teachers, students and parents can tell us about what happened and where to next 
for New Zealand's school system. The Education Hub. https://theeducationhub.org.nz/wp-content/uploads/2020/08/Learningfrom-lockdown.pdf.

Flack, C. B., Walker, L., Bickerstaff, A., Earle, H., \& Margetts, C. (2020). Educator perspectives on the impact of COVID-19 on teaching and learning in Australia and New Zealand. Pivot Professional Learning.

Fredricks, J. A., Blumenfeld, P., Friedel, J., \& Paris, A. (2005). School engagement. In K. Moore \& L. Lippman (Eds.), What do children need to flourish? (pp. 305-321). Springer.

Johnson, M. K., Robert, C., \& Elder, G. H. (2001). Student attachment and academic engagement: The role of race and ethnicity. Sociology of Education, 74, 318- 340. https://doi.org/10.2307/2673138

Kim, J., Walsh, E., Pike, K., \& Thompson, E. A. (2020). Cyberbullying and victimization and youth suicide risk: the buffering effects of school connectedness. The Journal of School Nursing, 36(4), 251-257. https://doi.org/10.1177\%2F1059840518824395

Li, S., \& Lajoie, S. P. (2021). Cognitive engagement in self-regulated learning: an integrative model. European Journal of Psychology of Education, 1-20. https://doi.org/10.1007/s10212-021-00565-x

Libbey, H. P. (2004). Measuring student relationships to school: Attachment, bonding, connectedness, and engagement. The Journal of School Health, 74(7), 274-283. https://doi.org/10.1111/j.1746-1561.2004.tb08284.x

Maiya, S., Dotterer, A. M., \& Whiteman, S. D. (2021). Longitudinal changes in adolescents' school bonding during the COVID-19 pandemic: Individual, parenting, and family correlates. Journal of Research on Adolescence, 31(3), 808-819. https://doi.org/10.1111/jora.12653

Merry, S. N., Cargo, T., Christie, G., Donkin, L., Hetrick, S., Fleming, T., HoltQuick, C., Hopkins, S., Stasiak, K., \& Warren, J. (2020). Debate: Supporting the mental health of school students in the COVID-19 pandemic in New Zealand-a digital ecosystem approach. Child and Adolescent Mental Health, 25(4), 267-269. https://doi.org/10.1111/camh.12429

Mutch, C. (2015). The impact of the Canterbury earthquakes on schools and school leaders: Educational leaders become crisis managers. Journal of Educational Leadership, Policy and Practice, 3(2), 39-55.

Page, A., Charteris, J., Anderson, J., \& Boyle, C. (2021). Fostering school connectedness online for students with diverse learning needs: inclusive education in Australia during the COVID-19 pandemic. European Journal of Special Needs Education, 36(1), 142-156. DOI: 10.1080/08856257.2021.1872842

Patel, K. (2020). Mental health implications of COVID-19 on children with disabilities. Asian Journal of Psychiatry. doi:10.1016/j.ajp.2020.102273 https://www.ncbi.nlm.nih.gov/pmc/articles/PMC7330593/ 
Radio New Zealand. (2020). Covid-19: Ministry of Education reveals support plans for distance learning. Retrieved from https://www.rnz.co.nz/news/political/413763/covid-19-ministry-ofeducation-reveals-support-plans-for-distance-learning

Tesar, M. (2021). Future studies: Reimagining our educational futures in the postCovid-19 world. Policy Futures in Education, 19(1), 1-6. https://doi.org/10.1177/1478210320986950

Victorian Department of Education and Training (VicDET) (2021) Lessons from Term 2 Remote and Flexible Learning. Retrieved from https://www.education.vic.gov.au/Documents/about/department/covid19/lessons-from-term-2-remote-learning.docx 


\section{ABOUT THE AUTHOR(S)}

\section{Jennifer Charteris \& Angela Page}

Learners, Learning and Teaching, University of New England, Australia

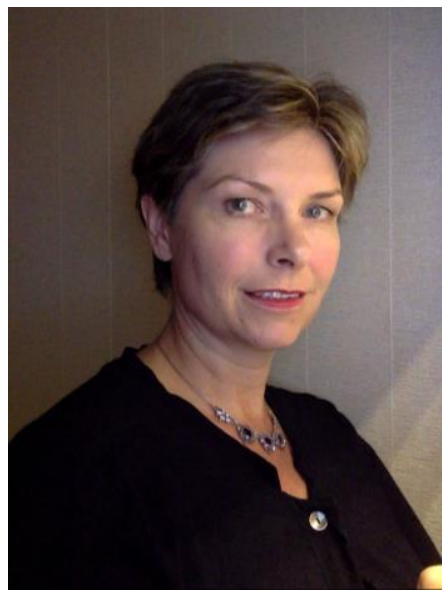

Associate Professor Jennifer Charteris is Head of Department, Learners, Learning and Teaching at the University of New England. She conducts research into how technology can assist teacher and student learning. As a teacher educator with teaching experience in Aotearoa/New Zealand, Australia and the UK, Jennifer has worked with students, teachers, principals, school communities and school in-service advisors across the primary, secondary and tertiary sectors. She researches in collaboration with educational leaders, teachers and students.

Contact: icharte5@une.edu.au

\section{Angela Page}

School of Education, University of Newcastle, Australia

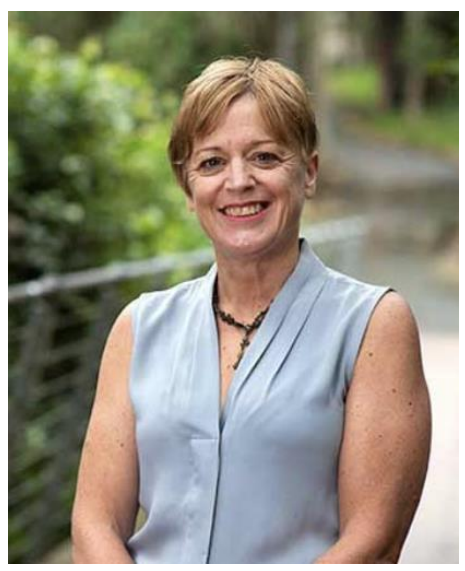

$\mathrm{Dr}$ Angela Page is a registered educational psychologist and works as a lecturer in Inclusive and Special Education at the University of Newcastle, Australia. She has worked as a secondary and specialist education teacher and advisor in New Zealand and the Pacific. Angela's research interests are in the areas of health and wellbeing for young people including mental health, and the development of positive relationships.

Contact: APage1@newcastle.edu.au

The opinions expressed are those of the paper author(s) and not the New Zealand Journal of Teachers' Work. Copyright is held by individual authors but offprints in the published format only may be distributed freely by individuals provided that the source is fully acknowledged. [ISSN-1176-6662] 